\title{
The drug-transporter gene MDR1 C3435T and G2677T/A polymorphisms and the risk of multidrug-resistant epilepsy in Turkish children
}

\author{
Mehmet Seven • Bahadir Batar • Selin Unal • \\ Gozde Yesil • Adnan Yuksel • Mehmet Guven
}

Received: 23 January 2013/Accepted: 5 November 2013/Published online: 10 November 2013

(c) The Author(s) 2013. This article is published with open access at Springerlink.com

\begin{abstract}
One-third of all individuals with epilepsy are resistant to antiepileptic drug (AED) treatment. Antiepileptic treatment response has been suggested to be modulated by genetic polymorphisms of drug efflux transporters. Several polymorphic variants within the multidrug resistance 1 (MDRl) gene, which encodes the major transmembrane efflux transporter P-glycoprotein, have been proposed to be associated with AED resistance in epilepsy patients. The aim of this study was to evaluate the effect of C3435T and G2677T/A polymorphisms of MDRl on AED resistance in Turkish children with epilepsy. MDRI C3435T and G2677T/A were genotyped in 152 patients with epilepsy, classified as drug-resistant in 69 and drugresponsive in 83. Genotypes of the C3435T and G2677T/A polymorphisms were determined by polymerase chain reaction followed by restriction fragment length polymorphism. Genotype and allele frequencies of C3435T and G2677T/A polymorphisms of the MDRl gene did not differ between drug-resistant and drug-responsive epilepsy patients. Our results suggest that MDR1 C3435T and G2677T/A polymorphisms are not associated with AED resistance in Turkish epileptic patients. To clarify the exact clinical implication of the MDRI polymorphisms on the multidrug resistance in epilepsy, further investigations in various ethnic populations would be necessary.
\end{abstract}

\footnotetext{
M. Seven · G. Yesil · A. Yuksel

Department of Medical Genetics, Cerrahpasa Medical Faculty, Istanbul University, Istanbul, Turkey

B. Batar $\cdot$ S. Unal · M. Guven $(\bowtie)$

Department of Medical Biology, Cerrahpasa Medical Faculty, Istanbul University, Istanbul, Turkey

e-mail: mgguven@istanbul.edu.tr; mguven66@gmail.com
}

Keywords Drug resistance - Epilepsy - MDR1 · P-gp · Polymorphism

\section{Introduction}

Epilepsy is one of the most prevalent serious chronic neurological disorders, effecting approximately 1-2\% of the population [1]. About $30 \%$ of patients with epilepsy do not respond to any of two to three first line antiepileptic drugs (AEDs) despite considerable advances in the therapy of epilepsy and these patients will develop refractory epilepsy [2]. Although efforts to predict pharmacoresistance have revealed several risk factors (an early onset of epilepsy, symptomatic or cryptogenic epilepsy, and generalized seizure) $[3,4]$, the mechanisms underlying the resistance to AEDs in the epilepsy treatment are still not well-understood.

Some potential mechanisms have been suggested regarding the transporters of the AEDs. There is accumulating evidence to suggest that an increase of functional expression of multidrug transporters produces pharmacokinetic changes that modify the access of AEDs to central nervous system targets [5]. Genetic polymorphisms in these transporters could account for their increased expression and/or functional activity. These genetic variations could be linked to changes on pharmacokinetic or pharmacodynamic of AEDs and effective responsiveness to AEDs [6].

The ATP-binding cassette (ABC) transporters, and especially $\mathrm{ABCB} 1$, are the focus of an international effort to establish their role in mediating drug resistance in a variety of human diseases including epilepsy [7]. Human multidrug resistant transporter gene (MDR1, also known as $\mathrm{ABCB} 1$ ), which is a member of the $\mathrm{ABC}$ superfamily, encodes a $170-\mathrm{kDa}$ P-glycoprotein (P-gp) [8]. The P-gp is 
of particular interest, and was first identified in cancer cells, as a protein responsible for resistance to a wide variety of AEDs [9]. The transmembrane P-gp that functions as a multispesific drug-efflux transporter is considered to be associated with drug absortion and elimination. It is hypothesized that overexpression of an efflux transporter such as P-gp around an epiloptegenic focus, via reducing AED accumulation, may prevent AEDs from entering sites of action [10].

The expression, efflux, substrate spesificity, and mRNA stability of P-gp are influenced by various single nucleotide polymorphisms (SNPs) in the encoding gene, MDRl [11]. Evidence is present for supporting the important role played by more gene polymorphisms on the function of P-gp via effecting its activity $[12,13]$. The $M D R 1$ gene is highly polymorphic with more than 50 variants residing in the coding region and, which can possibly cause altered function [14].

A great number of studies were focused on two most common SNPs, C3435T (Exon 26, rs 1045642) and G2677T/A (Exon 21, rs2032582) SNPs, to explore the associations with disease development and drug response in different populations [10]. The synonymous C3435T polymorphism was the first SNP, which has been shown to correlate with the expression levels and function of P-gp [15], although conflicting reports have subsequently appeared showing no correlation with the expression levels and function of P-gp [12]. The C3435T polymorphism is in linkage disequilibrium with nonsynonymous G2677T/A polymorphism (Ala893Ser/Thr), which may also contribute to the observed functional effect of variation at the C3435T polymorphism or at associated haplotypes [16]. Furthermore, the G2677T/A SNP has been shown to be associated with drug resistant epilepsy [17, 18]. Thus, the MDRl has been regarded as an interesting candidate gene potentially influencing the response to AED treatment.

Based on the hypothesis that MDRl genetic polymorphisms can modulate drug response phenotype in epilepsy, the present study was carried out to evaluate the association of two SNPs [3435C > T (rs1045642) and 2677G > T/A (rs2032582)] of the MDR1 gene in drug-responsive and drug-resistance patients in a Turkish population.

\section{Materials and methods}

Study population

A total of 152 Turkish children with epilepsy treated with AEDs were included in this study. The patients were diagnosed and classified according to the guidelines of the International League against Epilepsy. Patients, who had an established clinical diagnosis of epilepsy (defined by the occurrence of two or more unprovoked seizures) confirmed by an electroencephalogram examination by an expert were included in the study. Exclusion criteria consisted of severe adverse drug reactions, poor compliance with AEDs, history of pseudo-seizures, alcohol or drug abuse, or any other malignant diseases such as brain tumor, secondary metastasis, hepatic failure, or renal failure.

Patients were included if they had either drug-resistant or drug-responsive epilepsy according to the following definitions and criteria. The main criterion for drug resistance was the occurrence of at least four seizures over a period of 1 year with three AEDs, such as carbamazepine + valproate + levetiracetam, or carbamazepine + valproate + diphenyl hydantoin, according to the epileptic seizure type at maximum tolerated doses. Of the 152 patients, 69 were classified as drug resistant (40 males, 29 females, mean age: $9.2 \pm 3.6$ years) and 83 were drug responsive (51 males, 32 females, mean age: $9.3 \pm 3.8$ years.

The protocol for this study was approved by the Regional Ethics Committee and was carried out in accordance with The Code of Ethics of the World Medical Association (Declaration of Helsinki) for experiments involving humans. An informed consent was signed by each participant or responsible adult.

\section{Blood samples and DNA isolation}

Venous blood samples $(3 \mathrm{ml})$ were collected in EDTA vacutainer tubes for DNA extraction. Immediately after collection, whole blood was stored in aliquots at $-20{ }^{\circ} \mathrm{C}$ until use. Genomic DNA was extracted from leukocytes using Roche DNA purification kit (Roche Diagnostics $\mathrm{GmbH}$, Mannheim, Germany) according to the manufacturer's instructions.

\section{Genotyping}

Genotyping of MDRl C3435T (exon 26) and G2677T/A (exon 21) were determined by using the polymerase chain reaction-restriction fragment length polymorphism (PCRRFLP) assay. PCR amplifications of exon 26 and 21 of the MDRI gene were performed with primers described by Tanabe et al. and Cascorbi et al., respectively [19, 20]. PCR amplifications were carried out in a total volume of $25 \mu \mathrm{l}$ containing: $100 \mathrm{ng}$ of genomic DNA, 1U of Taq Polymerase (MBI Fermentas), $1 \mu \mathrm{M}$ of each primer [for C3435T, F:5'-TTG ATG GCA AAG AAA TAA AGC- $3^{\prime}$ and R:5'-CTT ACA TTA GGC AGT GAC TCG- $3^{\prime}$; for G2677T/A, F:5'-TTT GCA GGC TAT AGG TTC CAG-3', R(A):5'GTT TGA CTC ACC TTC CCA G- $3^{\prime}$ and R(T):5'TTT AGT TTG ACT CAC CTT CCC G-3'], 1X PCR buffer, $1 \mathrm{mM} \mathrm{MgCl}_{2}$, and $0.04 \mathrm{mM}$ dNTPs. The amplification reactions were performed in a thermocycler 9700 
(Applied Biosystems, California, USA) under the following conditions: For MDR1 C3435T polymorphism, initial denaturation at $94{ }^{\circ} \mathrm{C}$ for $4 \mathrm{~min}$, followed by 35 cycles each of $94{ }^{\circ} \mathrm{C}$ for $30 \mathrm{~s}, 56{ }^{\circ} \mathrm{C}$ for $30 \mathrm{~s}, 72{ }^{\circ} \mathrm{C}$ for $30 \mathrm{~s}$; and a final extension at $72{ }^{\circ} \mathrm{C}$ for $5 \mathrm{~min}$; for $M D R 1 \mathrm{G} 2677 \mathrm{~T} / \mathrm{A}$ polymorphism, initial denaturation at $94{ }^{\circ} \mathrm{C}$ for $3 \mathrm{~min}$, followed by 40 cycles each of $94{ }^{\circ} \mathrm{C}$ for $20 \mathrm{~s}, 55^{\circ} \mathrm{C}$ for $20 \mathrm{~s}, 72{ }^{\circ} \mathrm{C}$ for $30 \mathrm{~s}$; and a final extension at $72{ }^{\circ} \mathrm{C}$ for $5 \mathrm{~min}$. The PCR products were digested by restriction endonucleases of $\mathrm{MboI}$ at $37{ }^{\circ} \mathrm{C}$ (for C3435T), BanI at $37{ }^{\circ} \mathrm{C}$ (for G2677T) and $\mathrm{BsrI}$ at $65^{\circ} \mathrm{C}$ (for G2677A) for $3 \mathrm{~h}$ and analyzed with $3 \%$ agarose gel electrophoresis.

\section{Statistical analysis}

Mean and standard deviations (SDs) are presented in case of continuous variables. Differences between the means of the two continuous variables were evaluated by the Student's $t$ test. Chi square $\left(\chi^{2}\right)$ or Fischer's exact test (twosided) was used to compare the association between the genotypes and alleles in relation to the cases, and test for deviation of genotype distribution from Hardy-Weinberg equilibrium. $P$ values of $<0.05$ were considered statistically significant. The odds ratio (OR) and their $95 \%$ confidence intervials (CIs) were calculated to estimate the strength of the association. Statistical analysis was performed using a statistical software package, SPSS 16.0 (SPSS Inc, USA). Haplotype frequency analysis and linkage disequilibrium for the two $M D R 1$ polymorphisms were performed by using the Haploview 4.2 program.

\section{Results}

Basic demographic and clinical charecteristics of epilepsy patients with drug-resistant and drug-responsive are presented Table 1 . The groups were not significantly different with respect to the age and gender (all values of $P>0.05$ ).

No significant deviations from Hardy-Weinberg equilibrium were observed in epilepsy patients $(P=0.68$ for MDRl C3435T and $P=1.00$ for MDRl G2677T/A).

Table 2 shows the genotype and allele frequencies of the polymorphisms in MDRl gene for both drug-resistant and drug-responsive epilepsy patients. The distribution of MDR1 C3435T and G2677T/A genotypes within drugresistant $(P=0.76$ and $P=1.00$, respectively) and drugresponsive ( $P=0.88$ and $P=0.98$, respectively) groups were not significantly different from that under HaryWeinberg equilibrium. No statistically significant differences were detected for the genotype and allele frequencies of the polymorphisms in the MDRl gene between the drugresistant and drug-responsive groups.
Table 1 Demographic and clinical characteristics of epilepsy patients

\begin{tabular}{lll}
\hline Parameters & Drug-resistant $n(\%)$ & Drug-responsive $n(\%)$ \\
\hline Gender & & $51(61)$ \\
Male & $40(58)$ & $32(39)$ \\
Female & $29(42)$ & \\
Age (years) & & $9.3 \pm 3.8$ \\
Mean \pm SD & $9.2 \pm 3.6$ & $2-14$ \\
Range & $1-15$ & \\
Seizure type & & $24(29)$ \\
Partial & $24(35)$ & $59(71)$ \\
Generalized & $45(65)$ & \\
Etiology & & $40(48)$ \\
Idiopathic & $31(45)$ & $27(33)$ \\
Symptomatic & $29(42)$ & $16(19)$ \\
Cryptogenic & $9(13)$ & \\
\hline
\end{tabular}

$S D$ standard deviation

Table 3 lists the haplotypes of $M D R 1$ polymorphisms in the drug-resistant and drug-responsive epilepsy patients. Haplotype frequencies of these polymorphisms in the MDR1 gene did not differ significantly between drugresistant and drug-responsive epilepsy patients. The linkage disequilibrium test of two SNPs in MDRl (Rs1045642 and rs2032582) were in strong linkage disequilibrium $\left(\mathrm{D}^{\prime}=0.991\right)$.

\section{Discussion}

Drug-resistant epilepsy patients tend to be resistant to a broad range of AEDs with a varied mode of action $[5,7]$. The functional characteristics of non-specific drug transporter proteins could explain broader resistance across types of epilepsy and to a range of AEDs [21]. Among these transporter proteins, $\mathrm{P}$-gp is considered as one of the most potent contributer to the phenomenon of clinical drug resistance to AEDs.

Various genetic polymorphisms in the MDRl gene could be linked with altered in vivo transport activity of P-gp which may play a facilitatory role in drug-resistant epilepsy [6]. These genetic polymorphisms among epilepsy patients are likely to contribute to different responses in patients, who have similar epilepsy syndromes and are taking similar, or even the same, doses of medication.

So in the present study, we investigated two SNPs in MDRl gene in drug-resistant and drug-responsive epilepsy patients. Results of the present study demonstrated that genotype and allele frequencies of C3435T and G2677T/A polymorphisms of the MDRl gene did not differ between drug-responsive and drug resistant epilepsy patients. 
Table 2 Genotype and allele distribution of the MDR1 C3435T and G2677T/A polymorphisms in drug resistant and drug-responsive patients with epilepsy

$O R$ odds ratio, $C I$ confidence interval

\begin{tabular}{lllll}
\hline Genotype/allele & $\begin{array}{l}\text { Drug- } \\
\text { resistant } \\
n(\%)\end{array}$ & $\begin{array}{l}\text { Drug- } \\
\text { responsive } \\
n(\%)\end{array}$ & OR (95\% CI) & $P$-value \\
\hline C3435T & $17(25)$ & $22(26)$ & Ref. & \\
CC & $30(43)$ & $38(46)$ & $1.02(0.46-2.26)$ & 0.96 \\
CT & $22(32)$ & $23(28)$ & $1.24(0.52-2.93)$ & 0.63 \\
TT & 0.46 & 0.49 & Ref. & \\
C allele frequency & 0.54 & 0.51 & $1.13(0.65-1.97)$ & 0.67 \\
T allele frequency & & & & \\
G26677T/A & $17(25)$ & $20(24)$ & Ref. & 0.91 \\
GG & $32(46)$ & $36(43)$ & $1.05(0.47-2.33)$ & 0.69 \\
GT & $17(25)$ & $24(29)$ & $0.83(0.34-2.04)$ & 1.00 \\
TT & $1(1)$ & $2(3)$ & $0.59(0.05-7.07)$ & 0.60 \\
GA & $2(3)$ & $1(1)$ & $2.35(0.20-28.27)$ & - \\
TA & $0(0)$ & $0(0)$ & - & \\
AA & 0.49 & 0.47 & Ref. & 0.72 \\
G allele frequency & 0.49 & 0.52 & $0.90(0.52-1.58)$ & 1.00 \\
T allele frequency & 0.02 & 0.01 & $1.92(0.17-21.87)$ & \\
A allele frequency & & &
\end{tabular}

Table 3 MDR1 C3435T and G2677T/A haplotype frequencies in drug-resistant and drug-responsive patients with epilepsy

\begin{tabular}{llll}
\hline Haplotype & Frequency & $P$-value \\
\cline { 2 - 3 } & Drug-resistant & Drug-responsive & \\
\hline TT & 0.535 & 0.526 & 0.988 \\
CG & 0.409 & 0.404 & 0.972 \\
TG & 0.044 & 0.035 & 0.487 \\
CT & 0.012 & 0.035 & 0.235 \\
\hline
\end{tabular}

Furthermore, the results of this study also showed no haplotype association of these $M D R l$ polymorphisms with drug-resistant epilepsy.

The results from various studies focusing on the role of MDR1 C3435T and G2677T/A polymorphisms in AED responsiveness are conflicting. Consistent with the present study, several studies have found no significant associations between drug-resistance epilepsy and the MDR1 C3435T and G2677T/A polymorphisms [22, 23]. Two studies from Turkey also reported that there were no associations between the polymorphisms of the MDRl gene and drugresistant epilepsy [24, 25]. Similarly, Kim et al. [26] observed no association between the polymorphisms of G2677T/A and 3435C $>\mathrm{T}$ and drug resistance in Korean patients. However, contrary to the above studies' results, Hung et al. [17] found that $3435 \mathrm{C}>\mathrm{T}$ and $2677 \mathrm{G}>\mathrm{T}$ in the $M D R 1$ gene contributed to drug-resistant epilepsy. Siddiqui et al. [27] demonstrated that the frequency of the 3435CC genotype among drug-resistant patients (27.5\%) was significantly higher than in drug-responsive patients or nonepileptic controls (15.7 or $18.5 \%$, respectively) among Caucasian subjects. In contrast to these results, Kwan et al. [28] reported that patients with drug-resistant epilepsy had a higher frequency of the 3435TT genotype (16.7\%) in comparison to drug-responsive epileptics or nonepileptic controls (10.6 or $7.4 \%$, respectively). Furthermore, Seo et al. also demonstrated that drug-resistant epilepsy patients were significantly more likely to have the $\mathrm{T}$ allele and the TT genotype at C3435T when compared to drug-responsive patients (50 vs 27; 36.9 vs $16.7 \%$, respectively). In addition, Seo et al. [29] found that patients with drug-resistant epilepsy had higher frequencies of the TT genotypes at G2677T/A in comparison to the drug-responsive patients (26.2, $23.8 \%$, respectively).

The differences observed in these reports may be due to the ethnic differences in genotype/allele frequencies. Genetic polymorphisms often vary between ethnic groups. Ethnic differences in genotype frequency for the investigated polymorphisms might effect the results in genetic studies. Distribution of MDRl C3435T polymorphism also displays an ethnic difference. For example, MDR1 3435CC was less common than 3435TT in Caucasian patients (16-19 vs 27-33\% in drug-responsive patients) [22, 27], while the opposite of this was observed in Han Chinese cohort (38 vs $7 \%$ in drug responsive patients) [28], similar to other Asian populations [30]. Furthermore, contradictory data reported in these epidemiologic studies may be due to other several factors such as number of patients, combinations of susceptibility variants, the isolated nature of the study populations, heterogeneity of epilepsy and geneenvironment interactions. 
The authors assessed the association of MDR1 haplotypes derived from C3435T, G2677T/A, and C1236T loci in response to AEDs in different epilepsy populations [31]. In consistency with our results, Alpman et al. [25] found that the haplotypes of C3435T and G2677T/A were not associated with drug resistant epilepsy in Turkish epileptics. Furthermore, Meng et al. [32] failed to detect any associations between drug-resistance and haplotypes of C3435T, G2677T/A, and C1236T polymorphisms. However, Siddiqui et al. [27] reported that the C-G-C haplotype of C3435T, G2677T/A, and $\mathrm{C} 1236 \mathrm{~T}$ was associated with the AED-resistance. Zimprich et al. [18] also identified that $\mathrm{C}-\mathrm{G}-\mathrm{C}$ haplotype significantly increased the risk for pharmacoresistance. Contrary to this, Seo et al. [29] found that patients with drug-resistant epilepsy had higher frequencies of the T-T-T haplotype at C3435T, G2677T/A, and C1236T than patients with drug-responsive epilepsy (42.1, $30.4 \%$, respectively).

In conclusion, our results indicate that MDR1 C3435T and G2677T/A polymorphisms are not associated with drug-resistant epilepsy in the study population. The limitation of the current study is the small sample size. To clarify the exact clinical implication of the MDR1 polymorphisms on the multidrug resistance in epilepsy, further investigations in various ethnic populations would be necessary.

Acknowledgments This work was supported by the Research Fund of The University of Istanbul. Project number: 4228.

Conflict of interest The authors declare that there are no conflicts of interest.

Open Access This article is distributed under the terms of the Creative Commons Attribution License which permits any use, distribution, and reproduction in any medium, provided the original author(s) and the source are credited.

\section{References}

1. Browne TR, Holmes GL (2001) Epilepsy. N Engl J Med 344:1145-1151

2. Kwan P, Brodie MJ (2000) Early identification of refractory epilepsy. N Engl J Med 342:314-319

3. Regesta G, Tanganelli P (1999) Clinical aspects and biological bases of drug-resistant epilepsies. Epilepsy Res 34:109-122

4. MacDonald BK, Johnson AL, Goodridge DM, Cockerell OC, Sander JW, Shorvon SD (2000) Factors predicting prognosis of epilepsy after presentation with seizures. Ann Neurol 48(6):833-841

5. Remy S, Beck H (2006) Molecular and cellular mechanisms of pharmacoresistance in epilepsy. Brain 129:18-35

6. Lazarowski A, Czornyj L (2011) Potential role of multidrug resistant proteins in refractory epilepsy and antiepileptic drugs interactions. Drug Metab Drug Interact 26(1):21-26
7. Schmidt D, Loscher W (2005) Drug resistance in epilepsy: putative neurobiologic and clinical mechanisms. Epilepsia 46:858-877

8. Burger H, Foekens JA, Look MP, Meijer-van Gelder ME, Klijn JG, Wiemer EA, Stoter G (2003) RNA expression of breast cancer resistance protein, lung resistance-related protein, multidrug resistance-associated proteins 1 and 2, and multidrug resistance gene 1 in breast cancer: correlation with chemotherapeutic response. Clin Cancer Res 9:827-836

9. Ling V (1997) Multidrug resistance: molecular mechanisms and clinical relevance. Cancer Chemother Pharmacol 40:S3-S8

10. Sheng X, Zhang L, Tong N, Luo D, Wang M, Xu M, Zhang Z (2012) MDR1 C3435T polymorphism and cancer risk: a metaanalysis based on 39 case-control studies. Mol Biol Rep 39:7237-7249

11. Kimchi-Sarfaty C, Oh JM, Kim IW, Sauna ZE, Calcagno AM, Ambudkar SV, Gottesman MM (2007) A “silent” polymorphism in the MDR1 gene changes substrate specificity. Science 315:525-528

12. Sakaeda T (2005) MDR1 genotype-related pharmacogenetics: fact or fiction? Drug Metab Pharmacokinet 20:391-414

13. Schwab M, Eichelbaum M, Fromm MF (2003) Genetic polymorphisms of the human MDR1 drug transporter. Annu Rev Pharmacol Toxicol 43:285-307

14. Komar AA (2007) Silent SNPs: impact on gene function and phenotype. Pharmacogenomics 8(8):1075-1080

15. Hoffmeyer S, Burk O, von Richter O, Arnold HP, Brockmöller J, Johne A, Cascorbi I, Gerloff T, Roots I, Eichelbaum M, Brinkmann U (2000) Functional polymorphisms of the human multidrug-resistance gene: multiple sequence variations and correlation of one allele with P-glycoprotein expression and activity in vivo. Proc Natl Acad Sci USA 97:3473-3478

16. Soranzo N, Cavalleri GL, Weale ME, Wood NW, Depondt C, Marguerie R, Sisodiya SM, Goldstein DB (2004) Identifying candidate causal variants responsible for altered activity of the ABCB1 multidrug resistance gene. Genome Res 14:1333-1344

17. Hung CC, Jen Tai J, Kao PJ, Lin MS, Liou HH (2007) Association of polymorphisms in NR1I2 and ABCB1 genes with epilepsy treatment responses. Pharmacogenomics 8:1151-1158

18. Zimprich F, Sunder-Plassmann R, Stogmann E, Gleiss A, DalBianco A, Zimprich A, Plumer S, Baumgartner C, Mannhalter C (2004) Association of an ABCB1 gene haplotype with pharmacoresistance in temporal lobe epilepsy. Neurology 63:1087-1089

19. Tanabe M, Ieiri I, Nagata N, Inoue K, Ito S, Kanamori Y, Takahashi M, Kurata Y, Kigawa J, Higuchi S, Terakawa N, Otsubo K (2001) Expression of P-glycoprotein in human placenta: relation to genetic polymorphism of the multidrug resistance (MDR)1 gene. J Pharmacol Exp Ther 297:1137-1143

20. Cascorbi I, Gerloff T, Johne A, Meisel C, Hoffmeyer S, Schwab M, Schaeffeler E, Eichelbaum M, Brinkmann U, Roots I (2001) Frequency of single nucleotide polymorphisms in the P-glycoprotein drug transporter MDR1 gene in white subjects. Clin Pharmacol Ther 69(3):169-174

21. Ieiri I, Takane H, Otsubo K (2004) The MDR1 (ABCB1) gene polymorphism and its clinical implications. Clin Pharmacokinet 43:553-576

22. Sills GJ, Mohanraj R, Butler E, McCrindle S, Collier L, Wilson EA, Brodie MJ (2005) Lack of association between the C3435T polymorphism in the human multidrug resistance (MDR1) gene and response to antiepileptic drug treatment. Epilepsia 46:643-647

23. Kim DW, Kim M, Lee SK, Kang R, Lee SY (2006) Lack of association between C3435T nucleotide MDR1 genetic polymorphism and multidrug-resistant epilepsy. Seizure 15:344-347

24. Ozgon GO, Bebek N, Gul G, Cine N (2008) Association of MDR1 (C3435T) polymorphism and resistance to carbamazepine in epileptic patients from Turkey. Eur Neurol 59:67-70 
25. Alpman A, Ozkinay F, Tekgul H, Gokben S, Pehlivan S, Schalling M, Ozkinay C (2010) Multidrug resistance 1 (MDR1) gene polymorphisms in childhood drug-resistant epilepsy. J Child Neurol 25(12): 1485-1490

26. Kim YO, Kim MK, Woo YJ, Lee MC, Kim JH, Park KW, Kim EY, Roh YI, Kim CJ (2006) Single nucleotide polymorphisms in the multidrug resistance 1 gene in Korean epileptics. Seizure 15:67-72

27. Siddiqui A, Kerb R, Weale ME, Brinkmann U, Smith A, Goldstein DB, Wood NW, Sisodiya SM (2003) Association of multidrug resistance in epilepsy with a polymorphism in the drug transporter gene ABCB1. N Engl J Med 348(15):1442-1448

28. Kwan P, Baum L, Wong V, Ng PW, Lui CH, Sin NC, Hui AC, Yu E, Wong LK (2007) Association between ABCB1 C3435T polymorphism and drug-resistant epilepsy in Han Chinese. Epilepsy Behav 11:112-117
29. Seo T, Ishitsu T, Ueda N, Nakada N, Yurube K, Ueda K, Nakagawa K (2006) ABCB1 polymorphisms influence the response to antiepileptic drugs in Japanese epilepsy patients. Pharmacogenomics 7:551-561

30. Ameyaw MM, Regateiro F, Li T, Liu X, Tariq M, Mobarek A, Thornton N, Folayan GO, Githang'a J, Indalo A, Ofori-Adjei D, Price-Evans DA, McLeod HL (2001) MDR1 pharmacogenetics: frequency of the $\mathrm{C} 3435 \mathrm{~T}$ mutation in exon 26 is significantly influenced by ethnicity. Pharmacogenetics 11:7-21

31. Hung CC, Tai JJ, Lin CJ, Lee MJ, Liou HH (2005) Complex haplotypic effects of the $\mathrm{ABCB} 1$ gene on epilepsy treatment response. Pharmacogenomics 6:411-417

32. Meng H, Guo G, Ren J, Zhou H, Ge Y, Guo Y (2011) Effects of $\mathrm{ABCB} 1$ polymorphisms on plasma carbamazepine concentrations and pharmacoresistance in Chinese patients with epilepsy. Epilepsy Behav 21:27-30 